\title{
Implementation of Electric Vehicles in The Internal Route of The International University of Ecuador
}

\author{
Vladimir Azanza ${ }^{1,}{ }^{*}$, Álvaro Remache ${ }^{2}$, Soraya Ruiz ${ }^{3}$, Gorky Reyes ${ }^{4}$, Andrés Castillo $^{5}$ \\ $1,2,3,4,5$ Universidad Internacional del Ecuador, Quito - Ecuador \\ * corresponding author: edazanzalu@uide.edu.ec
}

\section{Article Info}

Received:

15 March 2021

Accepted:

25 May 2021

Published:

1 August 2021

DOI:

Presented in The $6^{\text {th }}$ International (Virtual) Workshop on UI GreenMetric World University Rankings (IWGM 2020)
Abstract Sustainable campuses have become one of the main objectives of agendas for a wide range of universities as a result of the impacts generated by the activities carried out within an academic life and how they directly affect the environment. An important aspect of the educational model of the International University of Ecuador, considering education as a focal transforming point of collective change, is to teach values and responsibility for the environment, considering that in terms of sustainability a higher education should not be understood only from the technical point of view, but as a process of realizing the significance of substantial values that would encourage future professionals to commit to the construction of a more fair and equitable society. For this reason, the objective of this study is to analyze sustainability through the implementation of electric mass transport vehicles in the internal route of the International University of Ecuador, for which the methodology is based on a quantitative approach, whose type of study is exploratory and of an inductive-deductive nature, analyzing the variables that directly influence a sustainable environment such as altitude above sea level (geographical location), benefited people, consumption and routes. Instruments such as sampling and surveys will be used to determine the decrease in polluting emissions that can affect the natural environment of the area. The technical considerations are the following: the location of the campus presents average slopes of $7.76^{\circ}$ at 2560 masl, the results of autonomy in a route are $14.8 \mathrm{~km}$ benefiting around 450 people a day from the university community, having an annual load consumption of 297311 KWh during day hours and of $114715 \mathrm{KWh}$ during night hours. With the implementation of an electric vehicle for the internal route, a power of 154.7 $\mathrm{KW}$ is required to overcome a slope of $18^{\circ}$ with a campus route of $178.4 \mathrm{~km}$, with this it would stop emitting 29.6 tons of $\mathrm{CO} 2$ and 0.76 tons of gases harmful for the environment per year.

\section{Keyword:}

Zero emission vehicles ZEV, reduction of polluting emissions, sustainability. 


\section{Introduction}

Polluting gases emission into the atmosphere with anthropogenic activities are the most probable causes of the variation in atmospheric temperature. The possible scenario by 2100 is an average increase of $3^{\circ} \mathrm{C}$ with respect to pre-industrial levels [1], [2]. Depending on the magnitude, the warming pacing, the geographical location, levels of development and vulnerability, the Intergovernmental Group of Experts on Climate Change IPCC warns that with a global warming of $2{ }^{\circ} \mathrm{C}$ there is a high risk for natural and human systems with lasting or irreversible impacts. For global warming not to exceed the $2^{\circ} \mathrm{C}$ limit, it is estimated that $\mathrm{CO} 2$ emissions have to be reduced by approximately $25 \%$ until 2030 and equal to zero around 2070 [3]. Limiting global warming to a $2^{\circ} \mathrm{C}$ increase will require farreaching and rapid transitions in energy, land, urban, infrastructure and industrial systems. Currently, the transport sector contributes with more than $25 \%$ and $55 \%$ of $\mathrm{CO} 2$ emissions worldwide and Ecuador, respectively [4] also causing an increase in mortality due to respiratory and cardiovascular problems associated with air pollution [5], for this reason it is important that private companies work on new sources of energy that benefit the environment.

The life cycle analysis for electric vehicles allows to know what the environmental impacts are considering the complete useful life. By examining different vehicle technologies, different effects on climate change, human health or mineral resource depletion can be assessed. Focusing the analysis only on climate change, battery electric vehicles can emit the same amount of emissions as internal combustion vehicles depending on the source of energy generation. However, if the source of electrical energy comes from renewable sources, emissions are greatly reduced [6]. Regarding electricity generation in Ecuador for the national interconnected system, this comes in more than $90 \%$ from renewable energy sources [7].

Therefore, adopting electric mobility would lead to a significant reduction in emissions, considering that in Quito alone the private cars represent $60 \%$ of the environmental impact generated by polluting gases. $35 \%$ to $40 \%$ are SUV vehicles, with displacements of two thousand cubic centimeters producing PM2.5 (particulate matter) which is above the values accepted by the Ecuadorian Air Quality regulations, for which reason to reduce the environmental impact of these vehicles it would be necessary to cut the impact produced by internal combustion engines by half, that is, $60 \%$ of private cars, in the same way $40 \%$ should use clean energy and thus reduce future levels of particulate matter, protecting the habitat and the natural environment [8]. In this sense, the International University of Ecuador has promoted an environmental management system in accordance with responsibilities with the environment, it proposes the adoption of electric mobility focused on the reduction of polluting emissions, therefore the objective of this study is the analysis of sustainability through the implementation of electric mass transport vehicles in the internal route of the Institution, In the Tbilisi conference (1997), in its final report, it announces that universities, as research centers and training of professionals, should They will respond to the environmental problems that society faces, having a special responsibility in the management and protection of the environment, in this way these educational centers must improve the use of their resources with the sole purpose of making the campus environmentally sustainable. Each university is then conceived as an institution that is concerned with mitigating the impacts generated by its activities and generating the application of institutional policies that are a model to be followed by other universities in the cities, in each country [9]. 
This paper based on a quantitative approach, analyzed the technical - economic variables in analyzing the different scenarios proposed to demonstrate the feasibility of the implementation of electric vehicles in the internal route of the University.

\section{Analysis of the information}

Data collection on each of the decisive factors for decision making. The present research is focused on the mobility of UIDE students, throughout the campus in relation to the use of vehicles with clean energy. It was carried out with an analysis of traffic, passenger flow, busiest times, distance of the route, times of movement between routes, provision of coverage for the implementation of recharging areas, current fleet of cars for the route, fuel costs and installed capacity of electrical energy and consumption. This data collection will assess the different numerical indicators in a quantitative way for the selection of the electric minibus, taking into account aspects such as autonomy, passenger capacity, economy of the vehicle, adequate infrastructure and budget.

The UIDE has several campuses nationwide, however for our study only the parent campus located in the city of Quito is considered on an area of 38 hectares at an altitude of 2560 to 2740 meters above sea level. The internal route connects the administrative buildings, classrooms, workshops, sports fields, and parking lots of the different 11 faculties through 4 stops and 2 lanes with a length of route of 1818.31 meters and an average slope of 7.76 degrees (see Fig. 1).

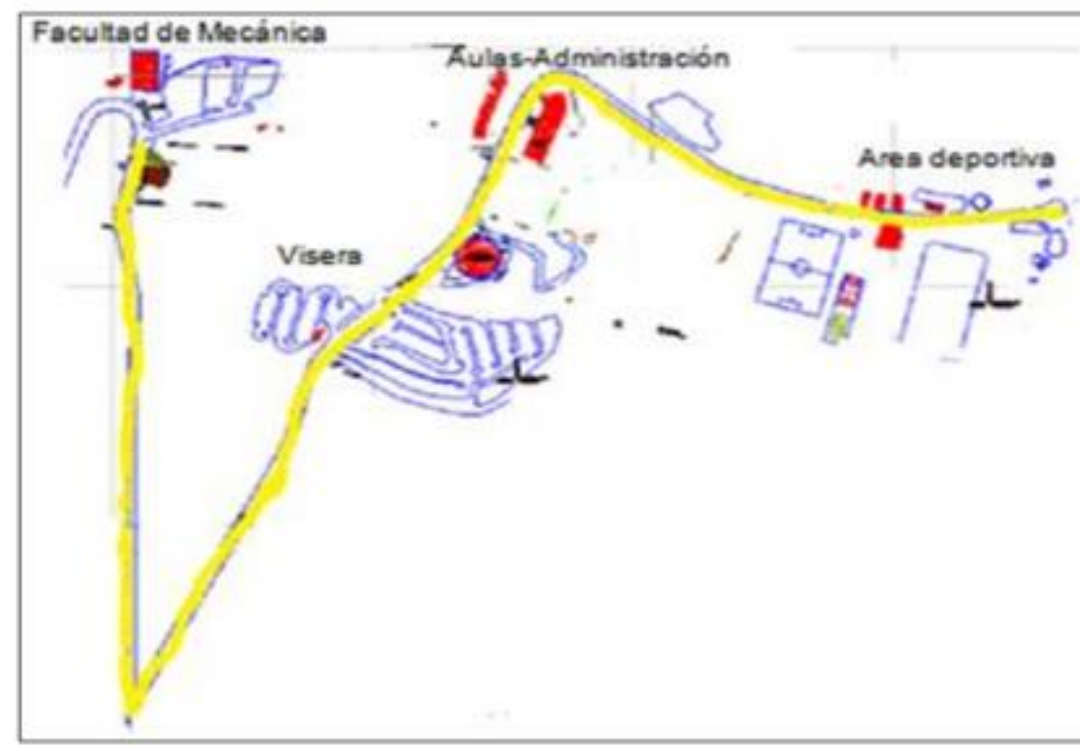

Figure 1. Internal transport route sketches

The analysis of the passenger flow activity has been possible under the method of exploratory study and interview with the person in charge of transport of the university, which helped to know the maximum distance traveled and the number of travel cycles demanded by users and It allowed taking actions regarding recharges, recharging points, use of extra battery banks, efficient use of transportation and energy storage.

In this way, the analysis of the availability of infrastructure conditioning for the charging points that must be implemented is carried out. Taking into account that by reducing the charge of the traction batteries, they are recharged in a minimum time of 6 
hours with slow charging to maximize the useful life of the battery. The time necessary to charge the battery, neglecting losses with a $3 \mathrm{~kW}$ charger, will be:

$$
t_{c h}=\frac{E_{\text {nom }}}{P_{c h}}
$$

The ideal points for the location of the central recharge in relation to the route, is in the first instance the part of the highest altitude of the UIDE, this being the school of automotive engineering mechanics and another point will be in the lower part, such as the areas sports (see Fig. 2) by placing these electroliers near the utility poles and lighting.
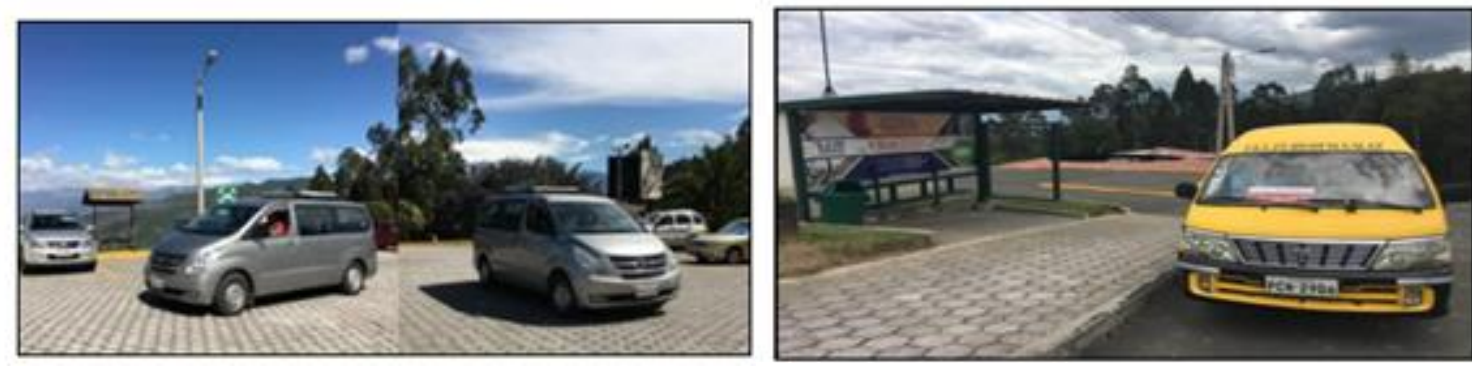

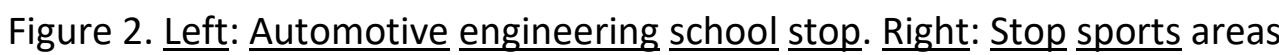

The current fleet of the UIDE internal transport department consists of two hyundai and kia brand vans with capacity for 12 and 17 passengers respectively. For the technical-economic analysis, aspects such as fuel costs, rental payments, traffic index and polluting gas emissions will be analyzed. Each van delivers 6 gallons of diesel per day, equivalent to $22.7 \mathrm{~L}$ of diesel. Taking into account that the unit of measure to be used is the one in force in Latin America, 3,785 liters are equivalent to 1 gallon per conversion. The fuel consumption for these vehicles is therefore:

$$
\underline{\text { Expense }}=\underline{\text { Distance }} \underline{\text { traveled }} / \underline{\text { fuel }} \text { consumed }=178.4 / 22.7 / 7.9 \mathrm{~km} / \underline{I}
$$

A gallon of diesel is priced at $\$ 3.10$ and daily consumption is 45.4 liters. Maintenance expenses will not be taken into account for the feasibility study as these expenses are not charged to the University's accounting and are assumed by the transportation service provider. However, the cost for transportation rental is $\$ 2850$ per month. The electric vehicle to be considered according to the variables analyzed is a Moto Electric Vehicles brand microbus of American origin equipped with a $7 \mathrm{~kW}$ motor with the ability to overcome slopes of 20 degrees at full load, reaching a maximum speed of $40 \mathrm{~km} / \mathrm{h}$ (see Fig. 3) with a range of $85 \mathrm{~km}$ and a battery capacity of $250 \mathrm{Ah}$ at $72 \mathrm{~V}$ since there are 12 batteries connected in series of $6 \mathrm{~V}$ each. 


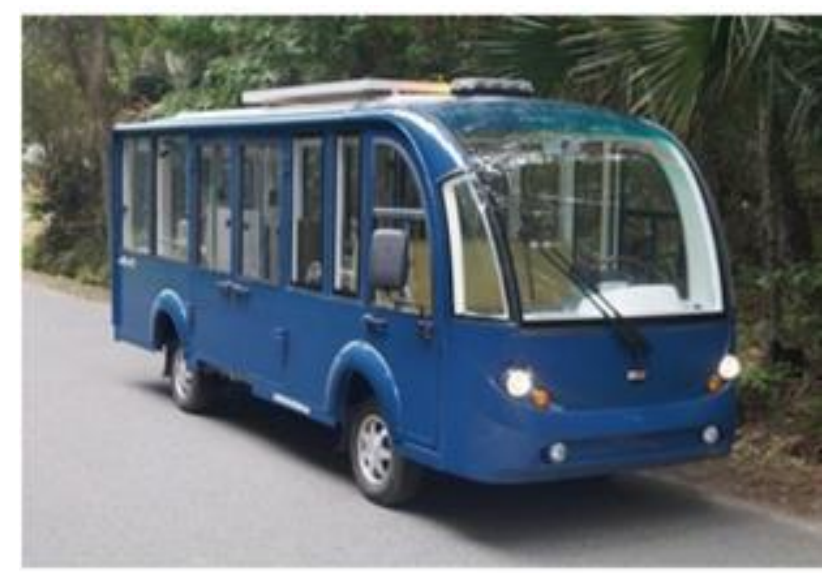

Figure 3. MotoEV electric minibus

The rated power capacity of batteries is:

$$
E_{\text {nom }}=Q_{\text {nom }} * V_{\text {nom }}=250 \mathrm{Ah} \cdot 72 \mathrm{~V}=18 \mathrm{kWh}
$$

\section{Viability analysis}

The total of passengers for different schedules throughout the day takes an average value of 10 passengers per vehicle (see table 1 ) where the transport service cycles are every 15 minutes. The days with the highest passenger movement are Monday, Tuesday, Wednesday and Friday, each bus travels a total of $178.4 \mathrm{~km}$ with a total number of trips of 49 times. Each bus consumes a total of 22.7 liters of average diesel per day, so the consumption rate is $7.9 \mathrm{~km} / \mathrm{I}$. Each liter of diesel consumed emits around 2,47 $\mathrm{kg}$ of $\mathrm{CO} 2$ into the environment. Therefore, each one of the buses emits $56.1 \mathrm{~kg}$ of $\mathrm{CO} 2$ into the environment, emitting an approximate of 296 tons of $\mathrm{CO} 2$ in a period of 10 years.

Table 1. Passengers transported per week

\begin{tabular}{ccccccc}
\hline & Monday & Tuesday & Wednesday & Thursday & Friday & Saturday \\
\hline Passengers & 571 & 485 & 668 & 387 & 506 & 235 \\
\hline
\end{tabular}

Among the technological limitations is the infrastructure of the distribution networks, where the high demand for electrical energy in peak hours would cause a possible deterioration and reduction of the useful life on typical distribution transformers. Thus, electric power flows will be controlled by charging electric vehicles at night. Taking into account that for this study in the transportation of people within the institution a MotoEv brand mini bus could be used, the economic valuation of its viability in the market is carried out, see Table 2, this analysis has been carried out through expenses for disbursements for the rental of internal transport but not for the income of the university.

Table 2. Market value of Moto EV minibus

\begin{tabular}{cc}
\hline & Moto EV \\
\hline Price $[\$]$ & 29995 \\
\hline
\end{tabular}

In this way, to identify the costs generated by the vehicle, the capacity of the traction batteries is considered, since it depends on energy consumption, and if we talk about the 
MotoEv mini bus, it has a capacity of $14.9 \mathrm{KWh}$ and autonomy up to $85 \mathrm{Km}$. So if we take into account that the daily route is $178.4 \mathrm{~km}$ on the identified route, the electric minibus needs to be recharged daily at night time. If necessary and according to the capacity of the batteries, recharges are required during daytime hours so that the energy demand would increase, in Table 3 one can see the energy consumption of the minibus in a recharge with the autonomy of $85 \mathrm{~km}$.

Table 3. Energy consumption costs

\begin{tabular}{ccccc}
\hline & $\begin{array}{c}\text { Cost of kWh } \\
{[\$]}\end{array}$ & $\begin{array}{c}\text { Charging time } \\
{[\mathrm{h}]}\end{array}$ & $\begin{array}{c}\text { Charging } \\
\text { power } \\
{[\mathrm{kW}]}\end{array}$ & $\begin{array}{c}\text { Cost of energy } \\
\text { consumption } \\
{[\$]}\end{array}$ \\
\hline Night rate & 0,062 & 6 & 3 & 1.12 \\
Daytime rate & 0,078 & 6 & 3 & 1.41 \\
\hline
\end{tabular}

To slowly recharge the conventional battery with single-phase alternating current, a power of $3 \mathrm{KW}$ is needed, if it is observed that the electric vehicle is going to be recharged 2 times a day, a total of 12 hours at a cost of $\$ 2.26$. If two electric vehicles are purchased, the daily cost of energy consumption is $\$ 4.52$.

\section{Conclusions}

Universities must develop a plan to reduce the impact generated on the environment by its growing population and the processes that are being developed, thereby encouraging university students to make a commitment to raise awareness to contribute to the control of energies that are harmful to the environment.

With the implementation of an electric vehicle for the internal route, a power of 154.7 $\mathrm{KW}$ is required to overcome a slope of $18^{\circ}$ with a route on the campus of $178.4 \mathrm{~km}$, with this, 29.6 tons of $\mathrm{CO} 2$ and 0.76 tons of gases would not be emitted harmful to the environment per year, opening the doors to sustainability, mobilizing around 2852 users per week within the campus.

\section{References}

1. J.colls, "Greenhouse gases and climate change," in Air Pollution, Taylor and Francis group, 2010.

2. S. A. Montzka, E. J. Dlugokencky, and J. H. Butler, "Non-CO 2 greenhouse gases and climate change," Nature. 2011, doi: 10.1038/nature10322.

3. IPCC, Calentamiento Global de 1,5 ${ }^{\circ} \mathrm{C} .2019$.

4. I. International Energy Agency, "CO2 emissions by sector," Web page. iea.org, 2020. https://www.iea.org/data-and-statistics/?country=WORLD\&fuel=CO2 emissions\&indicator $=\mathrm{CO} 2$ emissions by sector.

5. B. Giles-Corti et al., "City planning and population health: a global challenge," The Lancet. 2016, doi: 10.1016/S0140-6736(16)30066-6.

6. M. Messagie, F. S. Boureima, T. Coosemans, C. Macharis, and J. Van Mierlo, "A rangebased vehicle life cycle assessment incorporating variability in the environmental assessment of different vehicle technologies and fuels," Energies, 2014, doi: 10.3390/en7031467.

7. ARCONEL, "Balance Nacional de Energía Eléctrica a febrero 2020," 2020. [Online]. Available: https://www.regulacionelectrica.gob.ec/balance-nacional/. 
8. J. De Anda Sánchez, "Saneamiento descentralizado y reutilización sustentable de las aguas residuales municipales en México," Soc. y Ambient., 2017, doi: 10.31840/sya.v0i14.1770.

9. "Modelo de sistema de gestión ambiental para formar universidades ambientalmente sostenibles en Colombia.," Gestión y Ambient., 2011. 